\title{
Deliverable Factors of Manpower Requirement Plan: An Evidence from Indian EPC Company
}

\author{
Amruth Gurudev S ${ }^{\# 1}$, Srinivasa Rao Potti ${ }^{* 2}$, Shiva Prasad H.C \#3 $^{\# 3}$ \\ ${ }^{* 1}$ PG Research Scholar, Humanities and Management, \\ Manipal Institute of Technology, Manipal University, India \\ amruth14gurudev@gmail.com \\ ${ }^{* 2}$ Associate Professor, Department of Humanities and Management, \\ Manipal Institute of Technology, Manipal University, India \\ srinivasapotty@yahoo.co.in \\ \#3 Professor, Department of Humanities and Management, \\ Manipal Institute of Technology, Manipal University, India \\ hcs.prasad@manipal.edu (Corresponding author)
}

\begin{abstract}
This paper discusses the manpower plan required, and their deliverables factors to the clients of an Engineering Procurement and Construction in the process of designing for the construction of a thermal power plant, analyses the resource usage versus the planned allocated scheduled resources, resource levelling of scheduling. As a part of resource availability constraints in a critical path, method calendars were used to postpone activity start time, extend the activity duration that resulted in an increase of the project duration. A method of a forward pass has been proposed with the help of the Scurve diagram interpretation with the application of DMADV approach for resource levelling is illustrated with an activity-on-node as a case and a precedence diagram method. This research has elucidated on the critical issues of resource constrained levelling in the application domain of the project management in anticipation of deliverables from its employees to an EPC company. The findings of this research would provide useful inputs for the vendors and the consulting firm.
\end{abstract}

Keyword-: Critical method, Manpower planning, Resource levelling, S-curve

\section{INTRODUCTION}

Project management necessarily demands a reasonably structured succession of processes. The structured process is of utmost importance when considering a project organisation. The basis of control is made only by an organised and a planned method that represents the scope of work, resources required and financial plans. The project managers need to develop a schedule for directing and controlling resource of workers, machines and materials in a coordinated and a timely manner in order to deliver the project within the stipulated timeframe set by the client.

It is fact that with the complexity of the project, the project managers use related to project management software's like the Primavera Project Planner and M.S Project for analysing and scheduling using the critical path scheduling method [1]. The critical paths usually represented as CPM entails a forward pass to determine the total activities, the total duration for each of the activity involved with the Earliest Start Time (EST), and the Earliest Finish Time (EFT) for each of the activity and the resource assigned to the activity. The forward pass is ensured by the backwards pass for calculating Latest Finish Time (LFT) and Latest Start Time (LST) and Total Float (TF) for each activity. Total Float is defined as the maximum time that a delay could happen to complete the activity without disrupting and/or changing the total duration or total completion of the project. The activity with zero total floats are the critical activities of the project.

The CPM scheduling under resource limits constraints is generally referred to as resource allocation, which reschedules the project tasks based on the CPM analysis without resource limits constraints such as finite resources are efficiently utilized while keeping the extension of project duration to a constant [2]. Implicit resource driven, finish to start precedence relationships may exist between the activities due to the limited quality and quantity of the workforce. Taking into considerations, the factors involved a method is proposed for accurately determining the total float and the amount of manpower required to complete the given task and their effect on the activity with respect to the completion of the total project duration. 


\section{A. Problem Statements and Background}

During project execution phase the activities involved in the project are subjected to various uncertainties, and some of these activities might be dependent or independent in nature. This may lead to various disruptions in the scheduling of the project. The reality is in most of the companies lack the skilled resources needed to pursue the project hence this will lead to a considerable delay in the project completion thus increasing the cost to the company that will decrease the efficiency and the productivity of the firm. Without the knowledge of the labour availability and allocation, there is a danger that it may be unacceptable to the target group. Hence, it is a necessity to have a proper management practice to avoid these hurdles.

The objective of the paper is to analyze and standardize the deliverables factors of manpower requirement plan for an engineering procurement company that executes thermal power plant project.

\section{LITERATURE STUDY}

While organisations have to achieve an objective on time, then the projects control at the macro and the microenvironments is considered as a complicated task [3]. The resources such as people and tools need money and time. Therefore, project managers require a plan to attain the best use of resources needed to accomplish their projects. For a project to be successful, proper planning and a stringent method of selection are necessary that are done through the visualizations of plans by people who are going to be indulged in these projects. It will result in a conducive and a developmental atmosphere who are goal oriented, making official decisions grounded on an agreement and avoid discouragement, ignorance of plans and 'not modelled here' attitude [4].

The life cycle of developments is accordingly be portrayed utilising the s-curve that maps again in the other manner, i.e., development of income or gainfulness against time. In the early phase of a specific advancement, development is moderate as the new item makes itself [5]. Eventually, clients start to request and the item development increments all the more quickly. New incremental developments or changes to the item permit development to proceed. Towards the end of its life cycle, development moderates and may even start to decrease. In the later stages, no measure of new interest in that item will yield an ordinary rate of return [6].

The conventional CPM and PERT begin with an assumption of unlimited resources for every project activity [7], that means that the project plan is based on time demand of activities apart from the resource required for each of these activities. These activities have a critical path that helps us to indicate the overall project duration wherein most likely the resource allocation is overlooked. Problems arise when these activities have resources linked to them that will in turn act as the constraint and the needs of parallel activities cannot be achieved.

The Design For Six Sigma (DFSS) is a proactive approach for building a defect free product/process. It is a systematic approach to increase the quality of the process to exceed customer expectations and meet the goals and objectives of the company [8], with the sophisticated engineering tools that are universally accepted and comprises of the Define, Measure, Analyze, Improve and Control phases. These steps are uncovered in the methodology part.

As stated, meeting the project due date is extremely important in many industries. Equally important is accomplishing this in a cost-effective manner. One way in containing costs is to reduce the variability in the resource usage. The hiring and firing of employees on a short-term basis is very expensive [9].

In EPC projects, close monitoring of the project performance against the plan is the key tool used in identifying and mitigating risks in the project execution phase. The establishment of the schedule with a realistic baseline assigning the number of resources to the event/activity is essential for the success of a power project [11][12].

\section{III.RESEARCH METHODOLOGY}

The systematic way of solving a problem is called a Research methodology. It is a study of various steps that are adopted by a researcher in studying the research problem and approach with deductive or inductive logic to a problem. This section deals with the methodology used for this study. The steps followed are like the DMADV process. To understand it better a block diagram (see Fig.1).

1) Define- The scope of resource levelling, in this phase, the goals of the project, scope deliverables and the customers (external and internal) requirements are identified. In this phase, the project plan is developed the milestone activities are set, and the planned date of the release, i.e., that is the scheduled date are decided by the discussions with the clients. The quintessential customer requirements (CTQ's) are determined by the project heads and the respective department's heads. The resource to be allocated and the amount of each resource to be allocated is also set by the high-level meeting once the process is set into motion. 


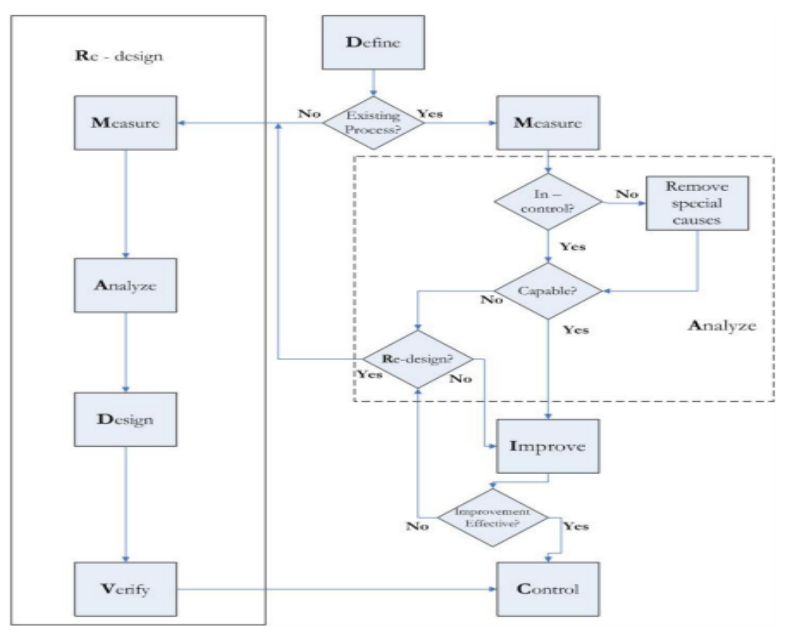

Fig. 1. DMADV approach for resource levelling

2) Measure- In this phase, the goals of the management are recorded and quantified. The defects are defined based on the revision process, opportunity and the units and the metrics is defined for the calculation of the existing resource utilisation of the firm. A data collection plan is made accordingly. The data is collected regarding the project and serves as an input to the MS Project as well as Microsoft Excel. The present working conditions the process utilisation and the total man hours consumed by the given project are identified that helps as an input to the analyse phase.

3) Analyze- The analysis phase involves defining the performance objectives. This is done by identifying the critical activities and the value and non-value adding activities. The sources of delays are identified. Identification of errors takes place, and evaluation of corrective measures and various other options are identified based on the S-curve as it gives out the result on the actual vs. planned dates of releasing the documents. This also helps in showing the delay components, and from this data, a new design or an improvement procedure are implemented for the following project.

4) Design- A new allocation procedure or a new process or a corrective step to the existing one is done to eliminate the defects, optimize the business process, reduction of cost related activities and meet the customer expectations.

5) Verify- Analyzing and standardization of resource constrained levelling. The levels and skills required and an available number of man-hours were defined as:

Level E8-Level E7: Top management activities, finance and fixing key responsibility areas.

LevelE6-Level E5: Quality audits and inspection, re-runs and management.

Level E4-Level E3: Specializations in a boiler, turbine and generator, the detailed working of the plant motors and equipment and safety protection.

Level E2-Level E1: Overall working, basic mechanical equipment knowledge, basic knowledge of the protection system, layout design, writes specification sheets and conveys the same.

Level E0: Prepare data sheet for the equipment.

6) Measure- Phase brought to light the importance of scheduling and backtracking of the dates for the completion of the required deliverables. This was done taking key inputs from both the Plant as well as management end. All relevant parameters such as man-power planning, a number of resources required for each activity/ event, the standard time required to complete the process and the revision dates were taken into consideration.

The Third phase involved calculating the progress report using suitable weights given by the client end and plotting the activities in a straight-line network diagram using the project management software like MS Project and PRIMAVERA scheduling for the resource utilization. Several man-hours spent required to complete the activity are listed and recorded to be found exceeding the quantity of the standard time given by the management.

In the design phase, a template regarding the man-hours spent by each designation of the engineer to the total allotted man-hour is created. A list of possible delays that caused the overshoot of the required time is found out by the expert opinion and recorded. The detailed activity list and a number of resources allocated to it were allotted and the critical path was found out. As it is strictly project oriented a resource levelling was conducted on the critical activities only that served as a symptomatic solution to the problem. 


\section{A. THE S-CuRve}

An S-curve at the initial stage displays slow, while accelerating its pace after certain period represents a slowing down as the number of variables becomes constant [5]. S-shape is the typical characteristics of this curve that is more or less flat at both the starting and at the ending with a slope in the middle, to plot this actual data collected was for eight months in the training period July to end of February month. S-curve is a display of the total cost or man-hours that are plotted against time.

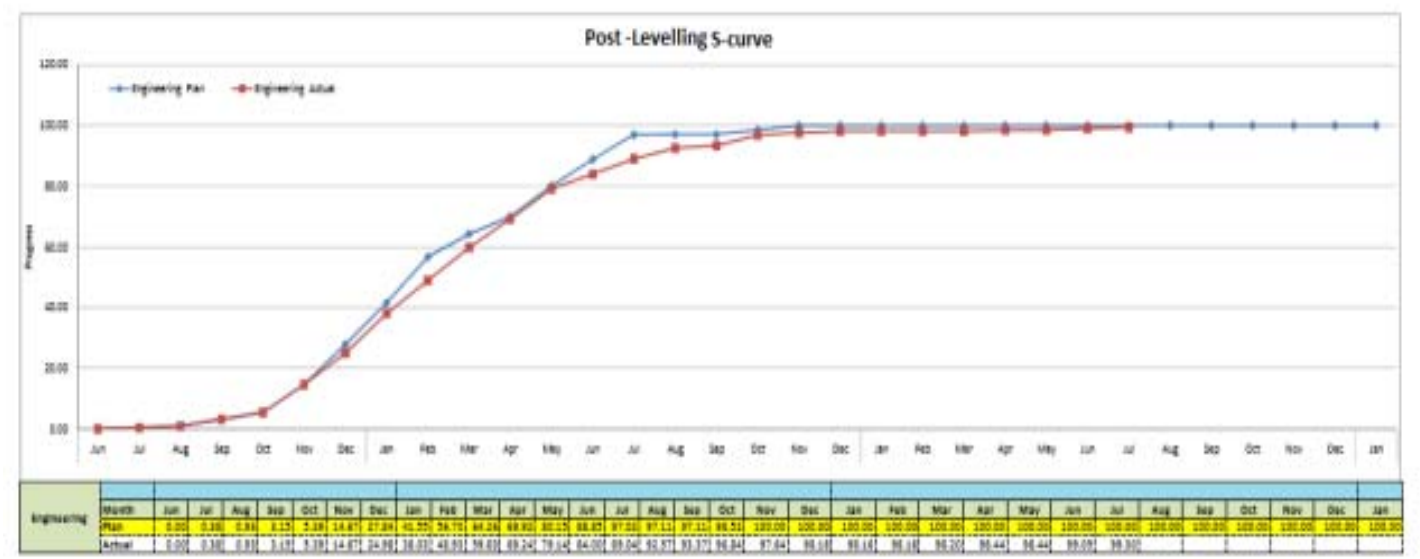

Fig. 2: S-curve post levelling process

The curve with dots legend is the planned dates agreed upon the company and the contractor (Fig. 2). Each weight is assigned as per the delivery of the scheduled document and based on this the S- the curve is plotted.

In contrast, the red curve in Fig. 2 shows the actual delivery of the scheduled documents after levelling of resources is done on the critical activities using M.S Project.

Since the process of levelling reduced the engineer's time required by four percent. There is a considerable change in the curve with respect to the changes made by the owner during the process of the project completion.

During calculating the S-curve, there were factors that indicated the delay of a certain group of engineers (E4E5) that were recorded as a knowledge base to the company

\section{B. THE PARETO ANALYSIS}

To arrive at a symptomatic solution, a detailed delay analysis was conducted using As-built vs. as planned method. With this Pareto analyses regarding the factors associated with delay were plotted.

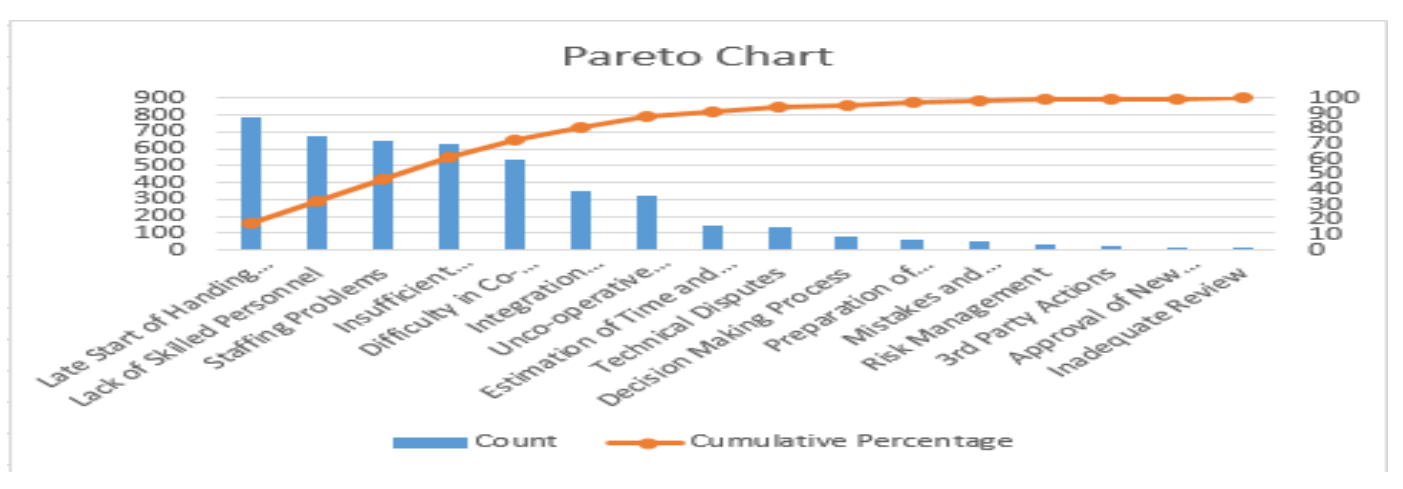

Fig 3: Pareto chart for delay in the deliverables

The Pareto analysis indicated the list of factors responsible for the delays in delivery of the engineering deliverables. The chart was prepared regarding a list of complaints and factors that were recorded during the study. This helped to give a fundamental solution to the underlying problem.

\section{ISHIKAWA DiAgRAm/FISH BONE Diagram}

The various reasons for the delay in scheduling the delivery of the documents were recorded and put it up pictorially with the help of a fish bone diagram or also better called as Ishikawa diagram. In the Fig. 4 the various delays regarding the delivery schedule have been classified and represented in the cause and effect diagram. It represents the various delays representing to the delay in the document schedule delivery to the client. 


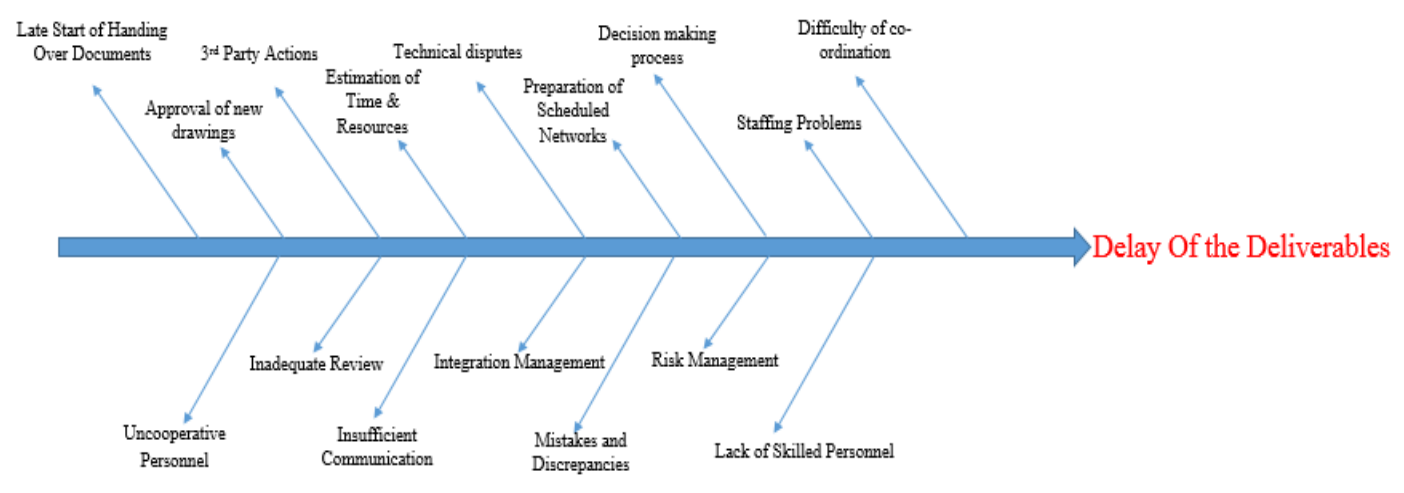

Fig. 4 Cause and Effect diagram

A wide variety of causes and effects regarding the delay of deliverables are considered in the project. These causes are related only to the man hour distribution of the preparation of the deliverables.

\section{IV.RESULTS AND DISCUSSION}

The proposed model useful helps in future to forecast the necessary requirements of a project. The model designed is utilized throughout the lifecycle of a project from beginning to the maturity stage to control the flow of resources, create and modify the detail project plan as well as stick to realistic guidelines. During the study, the percent overtime vs. percent over sales was calculated to be 10 percent. The percent defectives of the deliverables produced were found out to be four percent during the research. The data recording is an ongoing continuous process, but the scope of the research is limited to eight months only due to time constraints. A systematic plan for scheduling and allocation of Man-hours for the firm was done based on the constraints and the scope of the project. As of March 2015, the total overtime of the man-hours was reduced by four percent. The success of this also leads to the optimum use of the resource available as well as to shorter lead times in delivery of the engineering schedule deliverables. A plan to identify if the engineers need to be hired on a contractual or a permanent basis based on the requirements of the project is found out. It was able to predict the future requirements of the project. The trend is determined by the associated activity/event that aids in hiring and layoff of the engineers.

General wide depictions of delays regarding the handover of the engineering deliverables have been made using the fishbone diagram. Moreover, from the initial study, it is found out that engineers E4 and E5 have been contributing to the major delays in the process of delivering the scheduled deliverables.

\section{CONCLUSIONS}

Delay claims caused due to resource constraints are now a major source of conflict in the construction industry and one of the most difficult to resolve. As part of a wider research work, this paper seeks to develop such knowledge and understanding to solve the underlying issues. The reliability of the delay analysis results is validated by resource-loaded and levelled baseline programmes, these programmes provide reliable task duration, network logic, and realistic float values in non-critical activities as earlier researchers have done. While this case study uses a hypothetical project, the proposed claims scenarios largely reflect that of a typical construction delay claims settings, both in relevance and context and supports few investigation [13]. This study gets its strength, by conducting similar study being undertaken in future based on real life project data to validate the case study.

\section{ACKNOWLEDGMENT}

The authors would like to acknowledge a leading Indian Engineering Procurement Company for permission to use their data for this research and permission to publish this work.

\section{REFERENCES}

[1] R. Korman \& S. H. Daniels (2003). Critics can't find the logic in many of today's CPM schedules. Engineering News Record, 5(26), 30-33.

[2] T. Hegazy (1999). Optimization of resource allocation and leveling using genetic algorithms. Journal of construction engineering and management, 125(3), 167-175.

[3] M. Bandelloni, M. Tucci \& R. Rinaldi (1994). Optimal resource levelling using non-serial dynamic programming. European Journal of Operational Research, 78(2), 162-177.

[4] R. Burke (2003). Project management: Planning and control techniques, John Wiley \& Sons, (4th Ed.), ISBN 0470851244.

[5] H. Garland (1984). Relation of effort-performance expectancy to performance in goal-setting experiments. Journal of Applied Psychology, 69(1), 79. 
[6] C. Jayalath (2010). Understanding the S-curve of innovation. Retrieved from Improvement and Innovation. com. Verkkosivut: http://www. improvementandinnovation.com/featu res/article/understanding-s-curveinnovation.

[7] M. C. L. Abeyasinghe, D. J. Greenwood \& D. E. Johansen (2001). An efficient method for scheduling construction projects with resource constraints. International Journal of Project Management, 19(1), 29-45.

[8] C. M. Creveling, J. Slutsky \& D. Antis (2002). Design for Six Sigma in Technology and product development. River, NJ: Prentice Hall Professional.

[9] R. B. Harris (1978). Precedence and Arrow Networking Technique for Construction. 1st Ed., Hoboken, NJ: John Wiley \& Sons.

[10] S. I. Heisler (1994) The Wiley project engineer's desk reference: Project engineering, operations, and management, NY: John Wiley \& Sons. ISBN: 978-0-471-54677-1.

[11] G. Gendall (2003). The mysterious S-curve, Retrieved from http://www.maxwideman.com

[12] M. Hanna \& J. Y. Ruwanpura (2007, December). A simulation tool for manpower forecast loading and resource levelling. IEEE. Proceedings of the 2007 Winter Simulation Conference, edited by S. G. Henderson, B. Biller, M.-H. Hsieh, J. Shortle, J. D. Tew, and R. R. Barton. pp. 2099-2103.

[13] N. Braimah (2013). Construction delay analysis techniques-A review of application issues and improvement needs. Buildings, 3(3), 506-531.

\section{AUTHOR PROFILE}

Amruth Gurudev S has completed his post-graduation in Engineering Management stream from Manipal University. He is graduated from Dayananda Sagar College of Engineering with the specialization of Industrial Production Engineering. His research interest includes Quality, Six sigma, green belt application.

Srinivasa Rao Potti is an Associate Professor (Sr. Grade) in the Department of Humanities and Management, Manipal Institute of Technology, Manipal University, Manipal, India. He has BE in Mechanical Engineering, M Tech in Industrial Engineering. He has over 20 years of teaching experience and his research areas include education, best practices in engineering colleges, general management.

http://orcid.org/0000-0003-3653-5544 ; http://www.scopus.com/authid/detail.url?authorId=56296818900;

Shiva Prasad H C is a Faculty in the Department of Humanities and Management, MIT Manipal, India. He holds a PhD in Organization Behaviour from the Indian Institute of Technology, Kharagpur (West Bengal), India. World Business Institute of Australia has conferred him Fellowship for his research work. He was a member of the Board of National and International programs/workshops/conferences held at MIT Manipal. Published more than 22 articles in National and International Journal and has presented papers at both National and International conferences.

http://www.researcherid.com/rid/H-4739-2014;

http://orcid.org/0000-0002-1296-8970

http://www.scopus.com/authid/detail.url?authorId=54384313700; 